\title{
A study of the application of TAP combined with transvaginal ultrasound in the diagnosis of early-stage endometrial cancer
}

\author{
ANJUN MA $^{1 *}$, DIANXIA FAN ${ }^{2 *}$ and FANGLI YAN ${ }^{1}$ \\ ${ }^{1}$ Department of Gynecology, The Second People's Hospital of Liaocheng, Linqing, Shandong 252601; \\ ${ }^{2}$ Department of Gynaecology and Obstetrics, People's Hospital in Zoucheng, Jining, Shandong 273500, P.R. China
}

Received December 28, 2017; Accepted July 17, 2018

DOI: $10.3892 / \mathrm{ol} .2018 .9250$

\begin{abstract}
The aim of the study was to investigate the application of tumor abnormal protein (TAP) combined with transvaginal ultrasound in the diagnosis of early-stage endometrial cancer. A total of 248 patients with suspected endometrial cancer who were admitted to the Gynecology Department of the Second People's Hospital of Liaocheng from September 2013 to September 2015 were selected and randomly divided into the control $(n=124)$ and the observation group $(n=124)$. The control group received conventional ultrasound examination, while the observation, underwent TAP combined with conventional ultrasound examination. Differences in the definite diagnostic results of the two diagnostic methods and curettage were compared, and the application of TAP combined with transvaginal ultrasound in the diagnosis of early-stage endometrial cancer was studied. Among 248 patients receiving hysteroscopy and diagnostic curettage examination, there were 75 patients with early-stage endometrial cancer, and 173 benign patients. The total diagnostic accordance rate of conventional ultrasound for endometrial lesions was $87.90 \%(n=218)$, and the accordance rate for early-stage endometrial carcinoma was $90.67 \%(n=68)$; the total diagnostic accordance rate of TAP combined with vaginal ultrasound for endometrial lesions was $94.35 \%(\mathrm{n}=234)$, and for early-stage endometrial cancer was $94.67 \%$ ( $n=71$ ); of TAP combined with conventional ultrasound for endometrial lesions and endometrial cancer were higher than those of simple conventional ultrasound $(\mathrm{P}<0.05)$. The area under the curve (AUC) of conventional ultrasound in the diagnosis of endometrial cancer was 0.754 [95\% confidence interval (CI): 0.211-2.534]. The AUC of TAP combined with vaginal ultrasound in the diagnosis of endometrial cancer
\end{abstract}

Correspondence to: Dr Fangli Yan, Department of Gynecology, The Second People's Hospital of Liaocheng, 306 Jiankang Road, Linqing, Shandong 252601, P.R. China

E-mail: ynw2bq@163.com

*Contributed equally

Key words: vaginal ultrasound, endometrial cancer, hysteroscopy, application value, tumor abnormal protein was 0.814 (95\% CI: 0.517-0.932), and a comparison between the two groups was statistically significant $(\mathrm{P}=0.011)$. The accuracy rate of TAP combined with transvaginal ultrasound in the diagnosis of early-stage endometrial cancer is relatively high, and it is worthy promoting and applying in clinical practice.

\section{Introduction}

Endometrial cancer is a malignant tumor in the female reproductive system with a high incidence rate, accounting for approximately $25 \%$ of all the female reproductive system tumors, and its incidence in developed countries (ranking fourth) is higher than that in developing countries (ranking seventh) (1-2). Endometrial cancer often occurs in perimenopausal and postmenopausal women (3), and a present investigation report has shown that the age of patients at the onset of endometrial cancer becomes smaller and smaller (4). Although the five-year survival rate of patients has improved with the development of medical technology, the prognosis of some endometrial cancer patients is poor, causing death $(5,6)$; thus, the early diagnosis of endometrial cancer patients is crucial. The mortality rate of patients with endometrial cancer in the advanced stage is much higher than that of patients in the early stage (7). Improving the specificity and sensitivity of the diagnosis of endometrial cancer patients is an important means to improve the survival rate of patients.

Ultrasound plays an extremely important role in the diagnosis of tumors. Ultrasound has many advantages such as noninvasiveness, high diagnostic sensitivity, no radioactivity and simple methods. It has been widely used in the diagnosis of tumors $(8,9)$. In addition, ultrasound can reduce the invasive examination for patients and risks of invasive operation for patients through its initial screening (10). Tumor abnormal protein (TAP) is a kind of abnormal glycoprotein and calmodulin complex expressed after the mutation of oncogenes and tumor suppressor genes in cells (11). It has been reported that abnormal glycoproteins are closely related to the occurrence, development, invasion, metastasis and prognosis of cancers (12). Therefore, the detection of TAP in serum can provide an important reference for the clinical diagnosis of tumors.

In the present study, 248 patients with suspected endometrial cancer who were admitted to the Gynecology Department 
Table I. Clinical data of patients.

\begin{tabular}{lc}
\hline Clinical data & Control group $(\mathrm{n}=124)$ \\
\hline Age (years) & $41.6 \pm 11.6$ \\
Definite diagnostic results & \\
Endometrial polyps & 60 \\
Endometrial hyperplasia & 96 \\
Uterine fibroids & 17 \\
Endometrial cancer & 75 \\
Nationality n (\%) & \\
Han & $219(88.31)$ \\
National minority & $29(11.69)$ \\
Place of residence $\mathrm{n}(\%)$ & \\
City & $165(66.53)$ \\
Countryside & $83(33.47)$ \\
Menopausal status n $(\%)$ & \\
Premenopause & $43(17.34)$ \\
Postmenopause & $205(82.66)$ \\
\hline
\end{tabular}

of The Second People's Hospital of Liaocheng (Linqing, China) from September 2013 to September 2015 were selected, and the diagnostic accordance rate of TAP combined with vaginal ultrasound was analyzed.

\section{Materials and methods}

Clinical data. A total of 248 women patients (average age of $41.6 \pm 11.6$ years) with suspected endometrial cancer who were admitted to the Gynecology Department of The Second People's Hospital of Liaocheng from September 2013 to September 2015 were selected and randomly divided into the control $(n=124)$ and the observation group $(n=124)$. The control group received conventional ultrasound examination; the observation, underwent TAP combined with conventional ultrasound examination, and all patients were definitely diagnosed by hysteroscopy and diagnostic curettage examination. Patients without tumor history, without liver, kidney and other organ dysfunction, and without abnormal hemorrhage or coagulation dysfunction before operation were included. Patients with unqualified curettage specimens, receiving treatment before, with excessive large tumor mass or with other pulmonary or chest wall diseases were excluded. This study was approved by the Ethics Committee of the Second People's
Hospital of Liaocheng, and patients or their family members signed informed consent.

Instruments and methods. Hitachi Hivision Avivs color Doppler ultrasound diagnostic machine (Hitachi, Ltd., Tokyo, Japan) was applied for conventional ultrasound examination so as to observe patients' tumor diameter, shape, edge status, internal echo information and whether there were space occupying lesions. At the same time, the fasting whole blood was collected from the included patients in the early morning, and TAP detection was conducted. Abnormal carbohydrate chain glycoprotein detection kits were purchased from Thermo Fisher Scientific, Inc., (Waltham, MA, USA), and the image analyzer for TAP detection was purchased from Zhejiang Aicor Medical Technology Co., Ltd. (Zhejiang, China).

Statistical analysis. The experimental results were analyzed by using SPSS 22.0 software (IBM Corp., Armonk, NY, USA), and the analysis of variance followed by post hoc test (Least Significant Difference) was used for comparisons among multiple groups. Count data were expressed as percentage and detected by $\chi^{2}$ test. The sensitivity and specificity of conventional ultrasound and TAP combined with conventional ultrasound in the diagnosis of endometrial cancer were calculated, respectively. T0he diagnostic values of conventional ultrasound and the combination of the two methods in the diagnosis of endometrial cancer were studied by using the receiver operating characteristic (ROC) curve. $\mathrm{P}<0.05$ was considered to indicate a statistically sgnificant difference.

\section{Results}

Basic data. In this study, 248 patients at an average age of $41.6 \pm 11.6$ years with suspected endometrial cancer were included. After the pathological diagnosis by curettage, it was found that there were 60 cases of endometrial polyps, 96 of endometrial hyperplasia, 17 of uterine fibroids and 75 cases of endometrial cancer. In addition, the menopause data of patients were collected, in which there were 43 premenopausal patients $(17.34 \%)$, confirming that the age of patients at the onset of endometrial cancer becomes smaller (Table I).

Diagnostic results of the two programs. Of 248 patients receiving hysteroscopy and diagnostic curettage examination, there were 75 patients with early-stage endometrial cancer and 173 benign patients (including 60 patients with endometrial

Table II. Diagnostic accordance rates of TAP combined with conventional ultrasound and conventional ultrasound.

\begin{tabular}{|c|c|c|c|}
\hline Rate & $\begin{array}{l}\text { Conventional } \\
\text { ultrasound }\end{array}$ & $\begin{array}{l}\text { TAP combined } \\
\text { with conventional ultrasound }\end{array}$ & P-value \\
\hline Total diagnostic accordance rate & $218(87.90)$ & $234(94.35)$ & 0.031 \\
\hline Accordance rate of endometrial cancer & $68(90.67)$ & $71(94.67)$ & 0.047 \\
\hline Accordance rate of endometrial hyperplasia & $84(87.50)$ & $90(93.75)$ & 0.032 \\
\hline Accordance rate of endometrial polyps & $53(88.33)$ & $57(95.00)$ & 0.024 \\
\hline Accordance rate of uterine fibroids & $13(76.47)$ & $16(94.12)$ & 0.017 \\
\hline
\end{tabular}


Table III. Imaging manifestations of conventional ultrasound.

\begin{tabular}{|c|c|c|c|c|}
\hline & $\begin{array}{l}\text { Endometrial } \\
\text { polyps }\end{array}$ & $\begin{array}{l}\text { Endometrial } \\
\text { hyperplasia }\end{array}$ & $\begin{array}{l}\text { Uterine } \\
\text { fibroids }\end{array}$ & $\begin{array}{l}\text { Endometrial } \\
\text { cancer }\end{array}$ \\
\hline Uterine volume & $\begin{array}{l}\text { No obvious } \\
\text { increase }\end{array}$ & $\begin{array}{l}\text { No obvious change; } \\
\text { increase in some parts }\end{array}$ & Increased & $\begin{array}{l}\text { Obviously } \\
\text { increased }\end{array}$ \\
\hline Echo & $\begin{array}{l}\text { Hypoecho } \\
\text { Equal echo } \\
\text { Hyperecho }\end{array}$ & Slightly enhanced & $\begin{array}{l}\text { Hypoecho; } \\
\text { hyperecho in } \\
\text { tiny minority }\end{array}$ & $\begin{array}{l}\text { Unevenly } \\
\text { thickened }\end{array}$ \\
\hline Intimal thickness & $\begin{array}{l}\text { No significant } \\
\text { change }\end{array}$ & Thickened & Thickened & Thickened \\
\hline Lesion border & Clear & $\begin{array}{l}\text { Clear uterine } \\
\text { cavity line }\end{array}$ & $\begin{array}{l}\text { Relatively } \\
\text { clear }\end{array}$ & $\begin{array}{l}\text { Rough surface; } \\
\text { some unclear or even } \\
\text { vanished borders }\end{array}$ \\
\hline $\begin{array}{l}\text { Lesion area } \\
\text { liquidation/ } \\
\text { calcification }\end{array}$ & $\begin{array}{l}\text { Calcification in } \\
\text { few lesion areas }\end{array}$ & $\begin{array}{l}\text { No liquidation/ } \\
\text { calcification }\end{array}$ & $\begin{array}{l}\text { Liquidation/ } \\
\text { calcification on in } \\
\text { few lesion areas }\end{array}$ & $\begin{array}{l}\text { Liquidation in } \\
\text { some lesion } \\
\text { areas }\end{array}$ \\
\hline
\end{tabular}

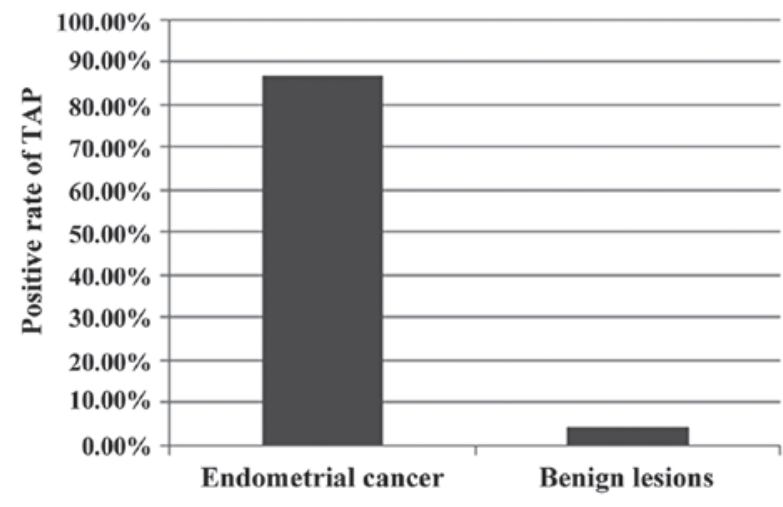

Figure 1. TAP detection results. The image analyzer for TAP detection is used to analyze the polarity of TAP detection results, which show that the positive rate of TAP detection in patients with endometrial cancer is $86.67 \%$ $(n=65)$ and in patients with benign lesions was $4.37 \%(n=8)$. There is a significant difference between the two groups of patients $(\mathrm{P}<0.05)$. Of the patients with benign lesions with positive TAP detection results, there are 5 cases of uterine fibroids, 2 of endometrial polyps and 1 of endometrial hyperplasia. TAP, tumor abnormal protein.

polyps, 96 with endometrial hyperplasia and 17 with uterine fibroids). The total diagnostic accordance rate of conventional ultrasound for endometrial lesions was $87.90 \%(n=218)$, and for early-stage endometrial carcinoma was $90.67 \%(n=68)$.For patients with endometrial polyps, the rate was $88.33 \%(n=53)$; with endometrial hyperplasia was $87.50 \%(n=84)$; with uterine fibroids was $76.47 \%(n=13)$. For TAP combined with vaginal ultrasound for endometrial lesions, the rate was $94.35 \%$ $(n=234)$, and for early-stage endometrial cancer was $94.67 \%$ $(n=71)$. For diagnosis for patients with endometrial polyps the rate was $95.00 \%(n=57)$, with endometrial hyperplasia it was $93.75 \%(n=90)$, and with uterine fibroids it was $94.12 \%$ $(n=16)$; The diagnostic accordance rates of TAP combined with conventional ultrasound for endometrial lesions were higher than those of simple conventional ultrasound $(\mathrm{P}<0.05)$ (Table II). Imaging manifestations of conventional ultrasound (Table III).

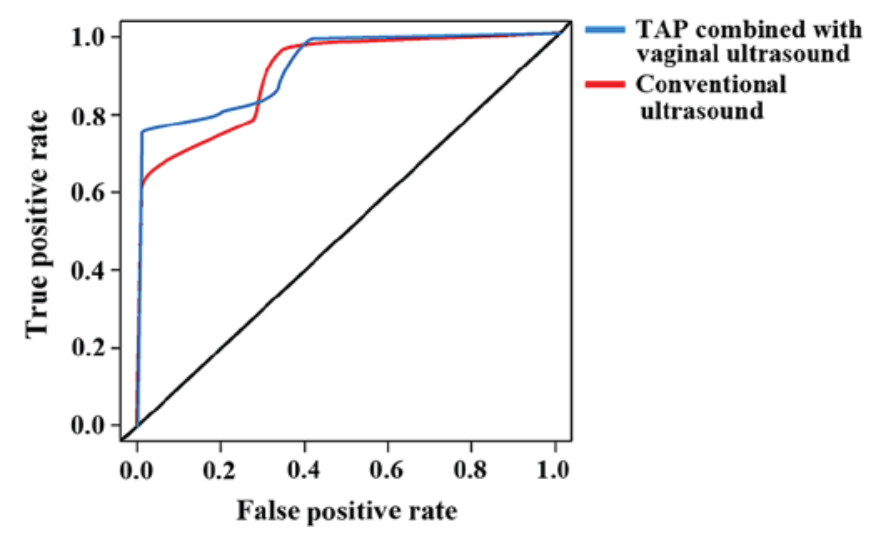

Figure 2. ROC curves of the two programs in the diagnosis of endometrial cancer. The AUC of convention ultrasound in the diagnosis of endometrial cancer is 0.754 [95\% CI: $0.211-2.534$ ], and that of TAP combined with vaginal ultrasound in the diagnosis of endometrial cancer is $0.814(95 \%$ CI: 0.517-0.932); the difference between the two programs is significant $(\mathrm{P}=0.011)$. ROC, receiver operating characteristic; AUC, area under the curve; TAP, tumor abnormal protein; CI, confidence interval.

TAP detection results. The image analyzer for TAP detection was used to analyze the polarity of TAP detection results, which showed that the positive rate of TAP detection was $86.67 \%$ $(n=65)$ in patients with endometrial cancer and $4.37 \%(n=8)$ with benign lesions; there was a significant difference between the two groups of patients $(\mathrm{P}<0.05)$. Among the patients with benign lesions and positive TAP detection results, there were 5 cases of uterine fibroids, 2 of endometrial polyps and 1 of endometrial hyperplasia (Fig. 1).

Sensitivity and specificity of the two programs. The sensitivity and specificity of conventional ultrasound to endometrial cancer were 85.7 and $89.7 \%$, respectively, and those of TAP combined with vaginal ultrasound to endometrial cancer were 90.0 and $92.8 \%$, respectively. ROC analysis results revealed that the AUC of convention ultrasound in the diagnosis of endometrial cancer was 0.754 [95\% confidence interval (CI): 
$0.211-2.534]$, and that of TAP combined with vaginal ultrasound in the diagnosis of endometrial cancer was $0.814(95 \%$ CI: 0.517-0.932); the difference between the two programs was significant ( $\mathrm{P}=0.011)$ (Fig. 2).

\section{Discussion}

Prognoses of endometrial cancer in the advanced stage and some special cases of endometrial cancer are very poor, and their 5-year survival rates are relatively low, so the early diagnosis of patients with endometrial cancer is very necessary $(6,7)$. TAP is a type of complex that is expressed and released by tumor cells and can be found in the blood of tumor patients, which provides a very convenient specimen for the early screening of tumors $(13,14)$. TAP has become a hot research object for researchers, especially on the screening and early diagnosis of tumors, since it was discovered by the Union of Soviet Socialist Republics (USSR) scholars, Kostyantin, A. and Galakhin $(15,16)$. However, there are few diagnostic studies in patients with endometrial cancer in the early stage. This study was expected to provide a basis for clinical diagnosis of endometrial cancer in the early stage and improve the survival rate of patients.

In the present study, 248 patients with suspected endometrial cancer were included, and with other tumors were excluded. TAP combined with conventional ultrasound was used for diagnosis, whose results were compared with those of diagnostic curettage detection, so as to analyze the value of TAP combined with conventional ultrasound in the diagnosis of endometrial cancer in the early stage. The study's results showed that the diagnostic accordance rate of TAP for patients with endometrial cancer was $86.67 \%$, and that of conventional ultrasound for patients with endometrial cancer was $90.67 \%$, and that of the combination of the two was $94.35 \%$; the diagnostic accordance rate of TAP and conventional ultrasound for patients with endometrial cancer were lower than that of the combination of the two $(\mathrm{P}<0.05)$, indicating that TAP detection can improve the diagnostic effect of conventional ultrasound on endometrial cancer. In addition, ROC curve results also revealed that the combined diagnostic method had a high diagnostic value $(\mathrm{AUC}=0.814)$. The sensitivity of the TAP detection system is the expressed TAP when the number of tumor cells reaches 100,000 and above, but it takes about one year for the number of tumor cells to proliferate to 100,000 before the tumor has not formed a mass, which is extremely important for the treatment and survival of patients, especially of those with malignant tumors with fast development and poor prognosis (17-20). There are few researchers studying the effect of TAP detection in the diagnosis of endometrial cancer in the early stage, so the conclusions in this study still need to be further validated. This study also had its advantages: All patients with past tumor history were excluded to avoid the interference in TAP detection; a selfcontrolled test was conducted so that the interference of test samples was avoided. TAP is also used in many kinds of cancers, such as gastric, thyroid and colorectal cancer, and it is of positive significance in improving the accordance rate of tumor diagnosis $(21,22)$. These indirectly confirmed the diagnostic value of TAP in the diagnosis of endometrial cancer. Benign endometrial lesions were also analyzed, which showed that approximately $20-40 \%$ of patients suffered from atypical endometrial hyperplasia before the onset of endometrial cancer. TAP combined with vaginal ultrasound also has a relatively diagnostic high accordance rate $(93.75 \%)$ for endometrial hyperplasia, and among patients with TAP positive detection results, there was 1 case of endometrial hyperplasia. Due to the limitation of experimental time, the patients were not followed-up, and further investigation is needed for confirmation of the results.

In summary, TAP combined with transvaginal ultrasound in the diagnosis of early-stage endometrial cancer has a higher accuracy rate, and it is worth promoting and applying in clinical practice.

\section{Acknowledgements}

Not applicable.

\section{Funding}

This study was supported by the Liaocheng Health Medical Letter [2016] No.3-146.

\section{Availability of data and materials}

All data generated or analyzed during this study are included in this published article.

\section{Authors' contributions}

AM and DF designed the study. DF and FY collected and analyzed the patient data. AM prepared the manuscript. All authors read and approved the final manuscript.

\section{Ethics approval and consent to participate}

The study was approved by the Ethics Committee of The Second People's Hospital of Liaocheng (Linqing, China) and informed consent was signed by the patients or guardians.

\section{Patient consent for publication}

Not applicable.

\section{Competing interests}

The authors declare that they have no competing interests.

\section{References}

1. Burke WM, Orr J, Leitao M, Salom E, Gehrig P, Olawaiye AB, Brewer M, Boruta D, Villella J, Herzog T, et al; SGO Clinical Practice Endometrial Cancer Working Group; Society of Gynecologic Oncology Clinical Practice Committee: Endometrial cancer: A review and current management strategies: part I. Gynecol Oncol 134: 385-392, 2014.

2. Colombo N, Creutzberg C, Amant F, Bosse T, González-Martín A, Ledermann J, Marth C, Nout R, Querleu D, Mirza MR, et al; ESMO-ESGO-ESTRO Endometrial Consensus Conference Working Group: ESMO-ESGO-ESTRO Consensus Conference on Endometrial Cancer: Diagnosis, treatment and follow-up. Ann Oncol 27: 16-41, 2016. 
3. McCarroll ML, Armbruster S, Frasure HE, Gothard MD, Gil KM Kavanagh MB, Waggoner S and von Gruenigen VE: Self-efficacy, quality of life, and weight loss in overweight/obese endometrial cancer survivors (SUCCEED): A randomized controlled trial. Gynecol Oncol 132: 397-402, 2014.

4. Chlebowski RT, Anderson GL, Sarto GE, Haque R, Runowicz CD, Aragaki AK, Thomson CA, Howard BV, Wactawski-Wende J, Chen $\mathrm{C}$, et al: Continuous combined estrogen plus progestin and endometrial cancer: The women's health initiative randomized trial. J Natl Cancer Inst 108: 350, 2015.

5. Plataniotis G and Castiglione M; ESMO Guidelines Working Group: Endometrial cancer: ESMO Clinical practice guidelines for diagnosis, treatment and follow-up. Ann Oncol 21 (Suppl 5): 41-45, 2010.

6. Carvajal-Carmona LG, O'Mara TA, Painter JN, Lose FA, Dennis J, Michailidou K, Tyrer JP, Ahmed S, Ferguson K, Healey CS, et al; National Study of Endometrial Cancer Genetics Group (NSECG); Australian National Endometrial Cancer Study Group (ANECS); RENDOCAS; Australian Ovarian Cancer Study (AOCS); GENICA Network: Candidate locus analysis of the TERT-CLPTM1L cancer risk region on chromosome 5p15 identifies multiple independent variants associated with endometrial cancer risk. Hum Genet 134: 231-245, 2015.

7. Suri V and Arora A: Management of endometrial cancer: A review. Rev Recent Clin Trials 10: 309-316, 2015.

8. Siddiqui MM, Rais-Bahrami S, Turkbey B, George AK, Rothwax J, Shakir N, Okoro C, Raskolnikov D, Parnes HL, Linehan WM, et al: Comparison of MR/ultrasound fusion-guided biopsy with ultrasound-guided biopsy for the diagnosis of prostate cancer. JAMA 313: 390-397, 2015.

9. Claudon M, Dietrich CF, Choi BI, Cosgrove DO, Kudo M, Nolsøe CP, Piscaglia F, Wilson SR, Barr RG, Chammas MC, et al: Guidelines and good clinical practice recommendations for contrast enhanced ultrasound (CEUS) - update 2008. Ultrasound Med Biol 39: 187-210, 2013.

10. Solomon SD and Saldana F: Point-of-care ultrasound in medical education-stop listening and look. N Engl J Med 370: 1083-1085, 2014.

11. El Hage F, Durgeau A and Mami-Chouaib F: TAP expression level in tumor cells defines the nature and processing of MHC class I peptides for recognition by tumor-specific cytotoxic T lymphocytes. Ann N Y Acad Sci 1283: 75-80, 2013.

12. Zhang L, Guo X, Min Y and Xu J: \& (TAP) examination contributes to primary diagnosis of bladder cancer. Int J Clin Exp Med 8: 18528-18532,2015.
13. Motoi T, Yoshida A, Motoi N, Kato I, Okuma T, Tonooka A, Horiguchi S, Goto T and Hishima T: Abstract 3542: Abnormal intracytoplasmic accumulation of autophagy-related protein p62/SQSTM1 characterizes giant cells of giant cell tumor of bone. Cancer Res 76 (Suppl 14): 3542-3542, 2016.

14. Doorduijn EM, Sluijter M, Querido BJ, Oliveira CC, Achour A, Ossendorp F, van der Burg SH and van Hall T: TAP-independent self-peptides enhance $\mathrm{T}$ cell recognition of immune-escaped tumors. J Clin Invest 126: 784-794, 2016.

15. Moniaux N, Andrianifahanana M, Brand RE and Batra SK: Multiple roles of mucins in pancreatic cancer, a lethal and challenging malignancy. Br J Cancer 91: 1s633-1638, 2004.

16. Hakomori S: Glycosylation defining cancer malignancy: New wine in an old bottle. Proc Natl Acad Sci USA 99: 10231-10233, 2002.

17. Dube DH and Bertozzi CR: Glycans in cancer and inflammation-potential for therapeutics and diagnostics. Nat Rev Drug Discov 4: 477-488, 2005.

18. Quail DF and Joyce JA: Microenvironmental regulation of tumor progression and metastasis. Nat Med 19: 1423-1437, 2013.

19. Rutkowski MR, Stephen TL, Svoronos N, Allegrezza MJ, Tesone AJ, Perales-Puchalt A, Brencicova E, Escovar-Fadul X, Nguyen JM, Cadungog MG, et al: Microbially driven TLR5-dependent signaling governs distal malignant progression through tumor-promoting inflammation. Cancer Cell 27: 27-40, 2015.

20. Liu J and Huang XE: Clinical application of serum tumor abnormal protein from patients with gastric cancer. Asian Pac J Cancer Prev 16: 4041-4044, 2015.

21. Liu Z, Cai J, Yu Y, Fang H, Si Y, Jankee JJ and Shen M: Tumor abnormal protein as a novel biomarker in papillary thyroid carcinoma. Clin Lab 63: 479-485, 2017.

22. Wu XY and Huang XE: Clinical application of serum tumor abnormal protein (TAP) in colorectal cancer patients. Asian Pac J Cancer Prev 16: 3425-3428, 2015.

This work is licensed under a Creative Commons Attribution-NonCommercial-NoDerivatives 4.0 International (CC BY-NC-ND 4.0) License. 